Lautaro Yankas

\title{
Pedro Luna y el misterio cromático
}

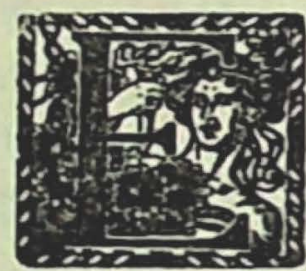

N UN SIGLO en que los caminos del hombre y la mujer - nunca fue más imperativa la definición del sexoestán jalonados y terminan en el signo moneda; en que estalla en la neurosis cuando no logra satisfacción clandestina o desembozada; en que el ideal apenas si vale como artimaña, manoseado y batido como una mayonesa para disimular la oscura intención, solemos advertir con asombro y no contenida emoción, la huella desafiante de una conciencia, de zonas no contaminadas, donde el espíritu y el instinto afirman su pulso original y su destino armónico. La verdad de que el pensamiento conduce al examen y la intuición a las revelaciones, condensa la fórmula de la angustia de nuestro tiempo, pues ambas facultades, desorbitadas, llevan al relajamiento del ideal y de la existencia. Nunca la humanidad devoró mayor cantidad de papel impreso, de novelería romántica, aventurera y truculenta, en desesperada búsqueda de un refugio y de un ritmo soportable para la mente dislocada. Mientras la novela de evasión invade la tierra como una plaga de moscas, el libro de análisis, la novela clínica interesa a los pocos que buscan una explicación al peligro de este tiempo. La desproporción del número es pavorosa.

La pintura, como la literatura, prolifera en forma parecida. Sólo el clasicismo carece hoy de beligerancia por su carencia de fuerza 
anímica. Lo sensorial y lo subjetivo imponen su medida a la plástica de este tiempo. Los valores estéticos derivan del virtuosismo técnico y contribuyen a lo absoluto en el cuadro. La emoción estética fluye de la secreta alquimia lograda por el temperamento, por el yo creador en su obra. Las escuelas se originaron en la sublimación de una sensibilidad excepcional que señaló caminos. Sobrevive lo personal; la característica de la escuela pasa a ser mera referencia.

Los "ismos" de hoy las emprenden con el arte de ayer como acostumbran los bandos políticos: con una declaración de principios. Esto es necesario, tal vez, porque la humanidad empleó hasta ayer su ojo físico para mirar el cuadro. En adelante deberá arriesgar su ojo mental para enfrentarse a un arte hecho con fórmulas geométrica - con transposiciones oníricas. Por fuerza evolutiva natural o por causa de la reacción negativa del espectador ante el cuadro "inteligente", los pintores cubistas, puristas, futuristas, han vuelito a interrogar el misterio del hombre, a su inquietud, a su vértigo, a su angustia. A la expresión de la inteligencia pura sucede la emoción del cuadro, la vibración sensitiva y su registro en el subconsciente. Sin embargo, como sucede hoy con la literatura y otras artes, el público busca la pintura de evasión y de gozo físico, sensorial y profundo, de reposo donde el ser recueste su alma para mirar hacia el mundo. El puerilismo, el impresionismo, el neoimpresionismo, el expresionismo, toda esta plástica sensorial y anímica, conquista a las mayorías, principalmente en América. Ello se explica, pues América yergue una geografía determinante, vale decir un paisaje y un conjunto de pueblos que imponen su carácter y su indeleble naturaleza en las obras y expresiones de su espíritu. Lo impusieron desde su prehistoria, porque esta tierra creó en ellos una potencia anímica entrañada, crisol de terrores y beligerancias. El hombre y el objeto construido por él llevan tal sello, expresión de su fuego interior. Con la Conquista nace un arte tocado de virginidad telúrica, de revelaciones constantes. La influencia europea, necesaria para la asimilación de técnicas, es desbordada por el contenido autóctono, vital, desmesurado. La desproporción de lo bárbaro, lo bravío, lo inmensurable, abruma en algunas 
obras literarias y pictóricas. Llegamos al siglo XX con algún jirón de "rastacuerismo" del XIX, luchando por un arte indoamericano dueño del espacio y del tiempo. El snobismo de muchos becados en Francia, Alemania e Italia queda reducido en ellos a la pugna de lo ajeno y postizo con la mediocridad o debilidad del temperamento. América acentúa su carácter. Los "ismos" valen acá como simples andamiajes de expresión plástica en la medida de las escuelas. En Chile, como sucede en el resto de América, el maderaje del andamio cruje y estalla, apenas maduran temperamentos como Alberto Valenzuela Llanos, Alfredo Valenzuela Puelma, Juan Francisco González y Pedro Luna, entre muchos otros. En México, los muralistas asombran a Europa. En Perú, José Sabogal plasma genialmente a su raza. En Bolivia, abisma la anímica pintura de Guzmán de Rojas, el maestro excepcional que extrae de la prehistoria y de la realidad terrígena sus apasionantes figuras. Cada cual, desde el risco nativo ruge su propio acento, mientras los esteticistas y teorizantes limpian su lupa sin poder encontrar la distancia, la medida ni el adjetivo.

Pedro Luna viene hasta nuestro tiempo desde la entraña de esta América musculosa y sana. No habríamos podido intentar el esbozo de su personalidad, sin ofrecer, como acabamos de hacerlo, una sugerencia histórica del medio físico y subyacente en que retozó su temperamento. Un país que en 1896, año en que nació Pedro Luna, era apenas un ensayo inestable de convivencia republicana, sujeto a principios y leyes de origen foráneo, anunciaba un destino tortuoso para el hombre, pues, en tales circunstancias el genio de la vida debía manifestarse con violencia, como sucedía a cada instante en esos años críticos que iban urdiendo la existencia de la nación. Hijo natural, estaba lejos de los hados propicios y no obstante, como ocurrió con más de un prohombre de esta tierra, el pulso vital superó los egoísmos y prejuicios y mostró a los suyos, a su madre principalmente, una porfía de predestinado en altura. Esta insurgencia suya, airosa, caracterizará aquellos momentos decisivos de su existencia incorruptible. El principio de "la vida reclama sus derechos", llegó a ser una ley mínima para el bullir de aquel muchacho nacido en un 
siglo de ardientes nebulosas. Todo estaba virgen en su entraña y habrían de correr los años antes de que su temple encontrase el espacio propicio para su impulso. Es preciso destacar esta acumulación de potencias en la breve medida del hombre para comprender más tarde al artista, al creador generoso y audaz. Su actitud superior en la vida, parecía respirar el lenguaje de su pintura.

Desde Los Angeles, la ciudad-fortín donde naciera, viaja a Santiago cuando tiene apenas tres años y crece en casa de sus abuelos, don Desiderio Luna y doña Sara Pérez Medina. La casona del Liceo "Santiago" (hoy "Valentín Letelier") lo vio balbucir sus primeros caprichos bajo la mirada indiferente de un maestro primario. Trasladado al Instituto Nacional a los diez años, repite el primer curso de humanidades y se gana la peor nota en dibujo. En 1910 no se sospechaba aún la existencia del espíritu diferenciado y de la libertad creadora en nuestra pedagogía. ¿Y ahora?... Me imagino el gesto abrupto del pequeño Luna pugnando por copiar en su hoja la figura impresa en el cartón colgado de la pizarra.

Pero el muchacho iba abriendo con fuerte puño la espesa maraña. Lo vemos en 1912, a los dieciséis años, como alumno en la Escuela de Bellas Artes, y en el Conservatorio Nacional de Música, siguiendo los cursos de piano y de órgano. No es preciso indagar detalles en el medio familiar para advertir la imposición de un carácter dentro del limitado círculo doméstico. Lo desusado, lo insólito, desbordaba los pequeños egoísmos, los temores, las decisiones sesudas de los parientes. Pero se requería, quizás, algún testimonio de mayor jerarquía para comprender y aceptar el ímpetu de aquel temperamento. Fernando Alvarez de Sotomayor, el maestro español que llegaba contratado por el gobierno chileno, nombra a Pedro Luna su ayudante. Hace años, charlando con Luna en su taller de la calle Recoleta, frente al cerro Blanco, me hablaba de su amistad con el maestro español y anotaba un juicio de éste durante la primera visita que ambos hicieron al Museo Nacional de Bellas Artes: "Recorríamos la sala de los pintores chilenos - me decía Luna con su fraseo saltarín y entrecortado- cuando el maestro se detuvo frente a los cua- 
dros de Valenzuela Puelma, "Magdalena", "Náyade" y "La perla del mercader". Permaneció largo rato examinándolos. "Pues, hombre, exclamó, estos cuadros estarían muy bien en los mejores museos de Europa".

En aquel tiempo Pedro Luna trabajó el croquis con Juan Francisco González. Siguió estatuaria elemental con Richón Brunet y J. M. Ortega; dibujo y pintura, con José Backaus Martin; paisaje, con Alberto Valenzuela Llanos; pintura y composición, con Julio Fossa Calderón. Pedro Lira y más tarde Alvarez de Sotomayor, fueron sus maestros en la cátedra superior de pintura. Entretanto, era nombrado dibujante oficial de la Escuela de Medicina.

El estímulo de sus amigos y de sus maestros lo lleva a exponer en 1913 junto con el español José Prida Solaris, Ulises Vásquez, Guillermo Maira y Abelardo Bustamante. Este último, bohemio impenitente, fatalista y escéptico, decía años después respondiendo a la halagadora incitación de sus amigos: "¿Para qué luchar por el arte, para qué trabajar cuando un genio aparece cada siete siglos?” Pedro Luna lo recordaba a menudo subrayando su talento, malogrado por el derrotismo y el alcohol. Fueron condiscípulos y los figones del barrio Bellavista y de Recoleta, así como el pintoresco "Teutonia", restaurante frecuentado por intelectuales, artistas y políticos de vanguardia, los vieron cascabelear su bohemia desdeñosa e inquietante, epilogada a veces en una comisaría o en un escaño del Parque Forestal. Había por ahí un rincón de artistas, donde la poesía, la música y la plástica libraban ardientes batallas, prestigiadas por nombres que habían de consagrarse muy pronto: Julio Barrenechea, Pablo $\mathrm{Ne}$ ruda, Roberto Meza Fuentes, el colombiano Claudio de Alas, Waldo Vila, Gonzalo Rojas, Remigio Acevedo (hijo) y algunos más. Pedro Luna, vecino de la iglesia "La Viñita", pasaba allí largas horas pulsando el órgano, pues amaba la música tanto como su vida libre; su temperamento se volcaba en aquel instrumento evocando a Bach, Beethoven, Mendelssohn o improvisando brillantemente.

La "generación del año 13", estrechamente unida a la promoción literaria del centenario, reúne a un grupo de artistas tan nutri- 
do y calificado que no es posible encontrar nada comparable en el historial de la pintura chilena y en el cual la personalidad de Pedro Luna empezaba a imponer su acento en medio de la contienda escolásticà en la cual el impresionismo, con sus sinfonías luminosas, parecía llevar la mejor parte. Condiscípulos de Luna todos ellos, algunos no lograron la máxima definición y otros desertaron llevándose, no obstante, algunos rasguños de la triunfal batalla. He aquí los nombres: Arturo Gordon, Andrés Madariaga, Guillermo Vergara, Enrique Bertrix, Exequiel Plaza, el ya mencionado "Paschín" Bustamante, Alfredo, Enrique y Alberto Lobos, Ulises Vásquez, Jaime Torrent, Francisco Alcalde, Jenaro Prieto, Luis Vargas Rozas, Ricardo Gilbert, Otto Giorgi, Laureano Guevara, Ximena Morla, Sara Camino de Backaus, Carlos del Campo, Luis Cousiño, Franz Dittrich, Ove Hangensen, Humberto Izquierdo, Julio Ortiz de Zárate, Agustín Abarca, Elmira Moisán, Jerónimo Costa, Manuel Gallinato, Jorge Madge, Camilo Mori, Fernando Meza, Luis Johnson, Enrique Moya, Emilio Alvarez, Ema Formas de Dávila, Oscar Millán, Estela Ross, Humberta Zorrilla, Judith Alpi, Nicanor Vergara, Carlos Izamit, Jorge Letelier, Fernando Toro, Eugenio Sepúlveda, Laura Rodig, Carlos Restat, Roberto Lorca y Gumercindo Oyarce.

Durante los años que precedieron a su "ruptura" con la capital, encontré muchas veces a Pedro Luna en su taller o en la calle y nunca dejé de admirar aquella complacencia vital que irradiaba su alto y recio cuerpo, siempre vestido de negro, y donde avizoraba una cabeza de rosados mofletes, pelo en raleados mechones y bajo la barbilla las alas negras de una corbata displicente. Nunca perdió aquella apostura, aquella señorial magnitud de su persona, que traducía la holgura de su espíritu y se definía certeramente en su vida amorosa. Alguno de sus contemporáneos recuerda la atracción lograda por Peđ̛ro Luna entre las mujeres. Su dominio de sí y su agilidad espiritual le abrían muchas puertas, infranqueables para la mayoría de sus amigos y compañeros. Los estragos no tardaron en manifestarse. Una mujer de arraigada familia, doña J. L. M. de W., arroja y quema su orgullo de dama y de esposa en la faunesca mirada del joven 
pintor. Una vez más, el hombre indómito y soberbio, asalta y pulveriza los obstáculos y en ello pone su gozosa vitalidad. Se formaliza el matrimonio religioso y sin muchas dilaciones la pareja viaja a Europa. Estamos en 1920. El dinero de la enamorada esposa se traduce en fiestas y delirio sobre ciudades y campos del Viejo Mundo. Como es lógico, allá nadie se asombra de ver a estos sudamericanos sedientos de vida y curiosos del arte. Mas, pronto se sabrá que este brioso viajero vale más que un simple bolsillo estrujable. Se le ve pintando en Roma con pupila certera y pulso cromático inusitado. En pocos meses y retozando junto a una mujer que lo requiere, Pedro Luna provoca el milagro: logra ser inscrito en la Exposición Internacional de Bellas Artes de Roma con su cuadro titulado "La nave roja", y como el impul'so llevaba mayor alcance, se gana con esta obra el Gran Premio Roma.

Permanece en Europa hasta comienzos de 1922. Su fama bien ganada, unida a su atractivo personal, le permiten interesar a la nobleza italiana y a personalidades del mundo intelectual y artístico. Las princesas Doria y Orsini, la condesa Magdalena Pagnoncalli se hacen retratar por el brioso y cálido pincel de Luna. Logra apuntes de Benedicto XV, del Cardenal Sam de Sanpere, de Pietro Mascagni, Ferruccio Busoni y de otros no menos famosos.

El artista empieza a ser dueño de sus medios y su ojo avizora en los museos el secreto signo de los elegidos, toma de las escuelas aquello que habrá de servir a su paleta inconfundible. El hombre, asimismo, superando lo doméstico y fácil, no vacila en arrancar a la vida sucesivas revelaciones, aquellas que sólo entrega al zahorí y al dominador. Su sensualidad corre alegremente y presta a sus nervios aquella salud piafante que retoza en sus cuadros. Naturalmente, su mujer debió advertir muy pronto el desvío del hombre que había vendimiado en el amor y en el dinero de ella, impulsado por su destino bravío e inasible. Aún más, la mujer comprendió que no lograría retenerlo, siquiera ocasionalmente. Meses después de su regreso a Chile, él se alejaba del hogar común. 
A mediados del año 1922, Pedro Luna presenta en Santiago su primera exposición. En 1923, en su taller de Teatinos 56, ofrece otra muestra con ochenta y ocho telas, resultado de su experiencia europea. La legítima aureola ganada en el extranjero y el personal carácter de su pintura, donde las virtudes plásticas se bañaban en una suerte de sofrenado demonismo, mantenían encendido el ambiente santiaguino, siempre sensible y curioso para la faena intelectual y artística. El taller de Luna alcanzaba en ese tiempo evidente atracción para los diversos grupos de iniciados y profesionales del arte $\mathrm{y}$, también, para la gente burguesa, la que obedecía en esto a una tradición, si no de mecenazgo, por lo menos de acercamiento e identificación con la jerarquía social del arte.

Braceando sin temores en esta atmósfera, tuvo la ocurrencia de invitar a su taller, acomodado para el caso, al Cuarteto de Londres que actuaba en Santiago, cuya fama y excelencias habían conmovido a los públicos del Nuevo Mundo. El pintor habíalos conocido en Europa y el director era amigo suyo. Quienes pudieron asistir a la fiesta la recuerdan como una apoteosis del arte y del espíritu. Un simple cóctel se transformó en nocturnal de valores humanos y de complacencia mundana, pues parecían haberse reunido allí todas las gracias de la vida. Fue una fiesta insolente para quienes no podían aceptar la presencia en ella de mujeres exquisitas, escapadas de las viejas mansiones santiaguinas, ni de varones viajados, portadores de las inquietudes y las ocurrencias que el siglo empezaba a consagrar.

En septiembre del año 1923 ofrece otra exposición. La casa de doña Sara del Campo de Montt, situada en la calle Bandera, esquina de Alameda, sirve para tal objeto. La cordial protección de la mencionada dama, permitió al artista un intenso trabajo y la tranquilidad de espíritu que parecía a veces serle necesaria, pues su bohemia parecía ir derivando hacia el disfrute de todo cuanto habla sido razón de su destino. El desorden y el alcohol lo acosaban. Así y todo, ese año 1923 marca sin duda el punto de ufano equilibrio entre la vida y el arte. El hombre, el "ente social", pese a sus violencias y fugas 
brutales, sostenía su dominio sobre el ambiente, que le toleraba y aun celebraba sus excesos.

A fines de 1923, da un nuevo envión a su existencia y se va al sur del país. Se le encuentra en el fundo "El Morro", próximo a Mulchén. En esta ciudad, estimulado por una acogida cordial, establece una academia de pintura. Algún tiempo después viaja a Traiguén, donde estrecha amistad con algunos profesionales, pedagogos y frailes y se gana la simpatía de todos. Pinta y vive sin reposo. Se adueña del órgano de la parroquia y allí se entrega a la evocación de sus genios predilectos. El párroco lo estimula, lo sabe su amigo y su hermano espiritual. Pinta en el convento de San Francisco el tema de "La Santa Cena", lo que no le impide decorar a continuación la casa masónica. A poco de llegar yo a Traiguén, en 1928, oía recordar con fruición las andanzas de Pedro Luna y sus ocurrencias que lo señalaron como el personaje más pintoresco conocido jamás en la región. El comerciante Maluf, viejo en la ciudad, me hablaba a menudo del pintor, pues mantuvo relaciones con él; la tienda proveía al artista de cuanto necesitaba el cuerpo y recibía en pago uno o más cuadros, pues Pedro Luna no regateaba su moneda. Durante los primeros años de mi permanencia en Traiguén me embelecé siempre en aquella pared de la tienda, encima de la estantería, pues estaba tapizada con cuadros de Luna en los cuales el paisaje sureño y el tipo mapuche concertaban su bárbara y fascinadora sugestión.

Tres años le lleva la aventura de Traiguén, lo que prueba la sensibilidad afectiva de Luna, así como la existencia en la pequeña y limpia ciudad sureña de una intimidad generosa para quien mostrase valores estimables.

Mas, el artista debía agotar el conocimiento de la provincia chilena. Las cartas a sus amigos hacen saber que ha llegado a Linares y se hospeda en casa de doña Celinda Duque de Salinas. Improvisa allí un taller y de nuevo se rodea de alumnos. Entre éstos estaba doña Rosaura Chaparro Pizarro, cuyas cualidades extrapictóricas interesaron particularmente al maestro y lo llevaron a su segundo matrimonio. En el hogar, Rosaura siguió cultivando la pintura y a ratos 
estudiaba violín, aunque el marido expresase su disconformidad con tales afanes por creer que nunca dejaría de embadurnar las mismas escenas románticas ni lograría arrancar su alado secreto al instrumento. Esta mujer adquiere un relieve indeleble en la existencia de Pedro Luna. El desorden de esa bohemia abismal que arrastraba al hombre, encontró en la compañera el paliativo cotidiano. El brusco tránsito entre lo sexual y lo doméstico nunca tuvo la aceptación del hombre, pero pudo soportarlo gracias a la denodada paciencia, a veces sublime, de la mujer.

En 1933, y a poco de casados, se establecen en Santiago. Pero la inquietud errabunda lo lleva en 1935 a Magallanes. En "la ciudad más austral del mundo", el pintor presenta una exposición, integrada en gran parte por trabajos inspirados en el paisaje y el hombre de aquellas latitudes.

Diríase que se produce el apaciguamiento definitivo en la naturaleza de Pedro Luna cuando a mediados de 1937 se acomoda con su mujer en la casona de su madre, ubicada en la Avenida Recoleta frente al cerro Blanco. Es una casa baja con tres patios y verja interior de hierro. Vive también alli su hermana. El influjo materno macera la inmersión del temperamento indócil en la beata quietud hogareña... En esa época llegamos más de una vez a la casa del pintor, el "palomar" como él lo bautizara. Era un altillo sobre las habitaciones que separaban el segundo patio del tercero. Tenfa tres piezas y dos corredores y se llegaba a él por una escalera en cuyos peldaños había tropezado con frecuencia la ya pesada humanidad de mi amigo. El taller tenía excelente luz de mañana y el pintor recibía allí a los amigos y clientes. Se charlaba sin fatiga mientras Luna pintaba o mostraba trabajos ya terminados. El botellón de vino traído desde el boliche cercano y algún comistrajo, creaban la temperatura peligrosa que alarmaba a Rosaura. Luna mostraba alli la misma plenitud física y anímica del año 23 en que fuera el señor de la bohemia santiaguina. Ardientes veladas en que el artista, derrơchando sus recuerdos, parecía dueño del tiempo infinito! Una tarde de primavera llegamos a su taller, cuando él pintaba una cabeza 
de mujer, obra de encargo. Nos recibió diciéndonos que aquel boceto le disgustaba. Se me ocurrió preguntar por la persona que servía de modelo para aquel trabajo y él torció el gesto: "Es una china desabrida, pero tiene plata"... Hicimos traer unas botellas de buen vino desde el negocio del italiano y entretanto alguien dio escape a una historia erótica en la que cierta mujer de insípida apariencia protagonizaba una escena salpicada de escabrosas menudencias. El pintor, que se había despachado un gran vaso de vino, sin abandonar su sitio ante el caballete, empezó de súbito a golpear la tela con toques rápidos, profundos, violentos, macerando, penetrando, atacando la imagen... El cuento seguía su curso. Se oía gruñir al pintor, que mordía impaciente su tosco cigarro... Minutos después, aquella cabeza del cuadro nos dejaba asombrados, pues se había convertido en una imagen de intensa gracia, velada por un sutil interrogante.

La muerte de doña Alba Luna, empuja al artista sobre sus propios designios. La casa es heredada por la hermana, tal vez para guardarla mejor; entretanto, el hermano se aferra a su altillo como a un islote tras el naufragio. Pasan todavía algunos años de trajines y roces familiares. Un buen día del año 1954 se despide de Santiago con destino a Viña del Mar. Su mujer va con él. Se siente dispuesto, como otras veces, a hilvanar la porfiada andanza de su libre existencia, de su sangre retozona y generosa. Su criolla robustez interior, clara y rica en humor, desconoce la amargura y no entiende la neurosis. La vida siempre le entrega un sabor virgen y sano y de ese modo la disfruta y la cástiga para ordeñarla golosamente, con sensitiva rudeza.

Sin embargo, su cuerpo, en sus cincuenta y ocho años indómitos, empieza a ser minado por el desorden de sus hábitos y por el alcohol. Cuando ya el erotismo ha mordido y calcinado sus mejores fuerzas, el destino insumiso cabalga sobre los espejismos de la bebida y del arte. Profundo y extraño connubio que aniquiló al hombre manteniendo erguido el ceño inspirador y creador. En Viña del Mar pinta como en sus mejores tiempos, logrando una musicalidad desconocida 
en su vuelo cromático. Los encargos se multiplican y de este modo puede llevar una existencia cómoda.

La cirrosis que lo atacó en 1954, no lo abandonará. El hombre no modifica su ritmo de vida, su fórmula de equilibrio superior. El mal es un "aparecido", un intruso. El vino constituye su antídoto moral. Pero el espíritu no es tan fuerte que logre detener la muerte física por la sola imposición de la soberbia. A la cirrosis se suma un cáncer de la garganta y esto señala el fin, en 1956.

Su mujer, digna del artista en su cabal dimensión por los desvelos rendidos al hombre, recibió de él su postrera y tierna evidencia: un cofre cerrado con setenta y ocho dibujos del artista. En la exposición efectuada después de su muerte esos dibujos dieron en remate una cantidad superior a los trescientos mil pesos.

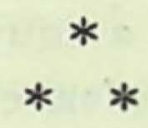

Hace ya algunos años, en nuestro "Itinerario de la pintura chilena” (1), enjuiciábamos al artista que motiva el presente estudio: "Pedro Luna, que recogiera la influencia de Valenzuela Llanos y Juan Francisco González, es, quizás, después de este último, el pintor que mayor y mejor substancia criolla haya vaciado en su ya fecunda obra. Todas las fuerzas que pugnan en esta lonja de tierra batida por el mar, agitan el temperamento y la vida de este artista insumiso, hoy recogido en sí mismo, distante de los grupos que señorean adjetivos y premios oficiales. Grande en su pasión por el color y en su desprecio por los rígidos dictados de las escuelas, Pedro Luna es a mi entender el tronco todavía sano en que debieran injertarse las estacas de la nueva generación, de esta generación mordida por las doctrinas y la neurosis constructiva. $\mathrm{Y}$ digo esto porque pienso que el

(1) Ensayo que obtuviera el Premio Historium en 1949, en el concurso internacional concertado por la revista argentina de ese nombre y publicado en febrero de 1950. Fue reproducido en Chile por la revista Occidente en junio del mismo año. 
arte, que es vida en sublimación, no debe olvidar la substancia, la sangre, que es base y función de vida. Para nosotros, la tierra es el primer fundamento de nuestra vida y de nuestro arte. En general, la pintura chilena ha brincado como un saltimbanqui y se ha colgado del trapecio despreciando el arraigo primario, burlando esta ley de gravitación de todo fenómeno sensible y de todo arte surgido en un continente virgen como es el nuestro. ¿Han creído nuestros pintores de hoy que la madurez de nuestros "clásicos" dio la justa contribución a la primera etapa de nuestra historia artística?"

Cuando fue publicado el ensayo a que me refiero, la atención del ambiente artístico estaba absorbida por la faena, muy encomiable, del grupo de pintores que, en su mayoría, recibieron durante su estada en Francia el profundo impacto de dos grandes maestros: Cézanne y Matisse. El cerebrismo picassiano y el lirismo decorativo de André Lothe habían herido a muy pocos. Las obras del mencionado grupo y su énfasis constituían el imperativo de los pocos críticos que nutrían el parecer colectivo. La muerte de Juan Francisco González, el maestro del dinamismo cromático, encendió algunas hogueras admirativas, lo que permitió una mejor valoración estética y... monetaria de su obra. Pedro Luna, entretanto, despegado insensiblemente de quienes se exhibían adornados de conceptos y de felices adjetivos, se arrellanó en una apacible penumbra, a donde nadie llegó a importunarlo. Los hombres y mujeres de la nueva hornada parecían olvidarlo. La Sociedad Nacional de Bellas Artes, atrincherada en los salones de La Alhambra, acogía algún envío de Luna y algunas de las recompensas del Salón Anual eran para él. La pugna entre el Salón Oficial y el ya nombrado, urdía la comidilla de la temporada. Los Premios Nacionales de Pintura, así como los de Música y de Literatura, eran disputados en tenebrosas y despiadadas campañas en las cuales la dignidad del artista se disgregaba. Sin embargo, por virtudes de magia, la lotería se ha ido repartiendo equitativamente entre las dos corrientes pictóricas dominantes: la tradicional (realista e impresionista) y la modernista que podría in- 
vocar el signo de Cézanne como distintivo capital, sin olvidar las otras divinidades portadoras de los últimos "ismos".

Por otra parte, las exposiciones de las salas comerciales indicaban la preferencia del público por la pintura de captación sensorial objetiva, lo que fustigaba la controversia. La excitación beligerante hacía olvidar el temperamento creador para atacar el principio o la raíz escolástica. No obstante, en ese momento no faltó quien se hiciera eco de lo que habíamos sentado en el estudio ya aludido. Tal vez porque examinados los valores cabales de uno y otro campo, se alzaban justamente dentro de la tendencia "colorista", encabezada por Pedro Luna, junto a Pablo Burchard (padre), Agustín Abarca, Luis Strozzi, Benito Rebolledo Correa y muchos otros, individualidades nítidas, vigorosas y dominantes.

Lo extraordinario es que hasta el año 1949, la crítica ni los organismos oficiales hubieran destacado como correspondía la obra valiosísima de los artistas nombrados y de otros que ya no se discuten. Hoy, en cambio, el oficialismo exhibe iniciativas, que rectificadas, orientadas hacia la realidad de nuestra historia plástica, habrán de merecer el elogio de todos. La explicación de aquello ya está dada y tal desinterés, condenable, sin duda, se repite con notable frecuencia en el historial artístico de otros países. La insurgencia de ciertos grupos, su vehemencia, se adueñan por largos períodos de la vida artística nacional, hasta que la natural fatiga del ambiente, no ajena a la ausencia de valores relevantes entre ellos, da paso sin esfuerzo a la exaltación de los creadores auténticos.

Esfumada la cortina de humo de ciertos modernismos arrogantes e impersonales en que la medida del talento quedaba reducida a la mera expresión de una doctrina plástica, no tardó en mostrarse con su decantada riqueza y dignidad, el brillante grupo de pintores que junto a Luna formaron la llamada "promoción del año 13" y cuyos nombres aparecen en líneas anteriores. Todos ellos resisten el más severo juicio y no rehúyen comparación con el grupo del año 40 ni con la promoción más reciente, inhibida como la anterior por la torturante "preocupación del cuadro". Convengamos, pues, en que 
tanto la crítica como el oficialismo cometieron el más negro de los errores al flirtear durante tantos años con el snobismo y el recetario plástico. Fue preciso que en las proximidades del año 1949, los diarios de París con su ironía inolvidable "elogiaran" a cierto grupo de pintores chilenos destacando su habilidad en copiar a los maestros franceses, para que nuestros críticos y mentores, tal vez ofendidos, volviesen los ojos hacia una auténtica pintura chilena, ya existente.

La personalidad de Pedro Luna empieza desde tal momento a mostrar sus recias aristas y su expresión dimensional. Aquellos que habían olvidado el Premio de Roma conquistado por Luna en plena juventud, se apoyaban ahora en tal suceso para definir la trayectoria ascendente del artista.

Conviene decir que la expresión cromática es ya sensible en las primeras obras de Pedro Luna. Señalemos la "Cabeza", pintada en la Escuela de Bellas Artes de Santiago, en 1919. Esta obra tiene del impresionismo el toque sugerente, ya certeramente dado, pero el color fluye conjugado por la briosa y cálida intuición del artista. Todo ello sobre un dibujo ágil y robusto. Se admira ya la combustión cromática y un signo interior, sano y latente, que retiene al espectador más frío. Otra cabeza, que lleva por título "La modelo", pintada en Roma en 1920, refleja ya el embrujo del color ambiental. El ultramar, el verde veronés, velan aquella cálida robustez primera.

Podríamos hablar de "la aventura europea" para subrayar esta época y su proyección en la obra realizada por Luna hasta algunos años después en Chile. Tras el regocijo experimentado ante la esplendidez cromática de la escuela veneciana, las obras maestras del impresionismo francés debieron conmoverlo en su errancia ávida de revelaciones. Las inefables transparencias de Monet y las plebeyas formas de Renoir, el neoimpresionista, ardieron en su crisol secreto.

Velázquez y Goya encontraron, asimismo, en su afán insurgente, un eco propicio. Esta primera época señala un proceso de combustión de valores expresivos y de técnicas. A través de la gama pura y del milagro atmosférico es ya perceptible la inquieta vivencia del creador. Pero para la mayoría es admirable la musicalidad 
dế color contenida en sus preferencias por el ultramar y el verde veronés, aplicados con inédita complacencia, armonizados entre gamas doradas. Afirmamos esto en presencia de algunas de sus telas más notables fechadas en esta época: "El Vaticano, desde el puente Miguel Angel” (1921), "Catedral de Marsella, desde el puerto" (1921), "Puerto de Marsella" (1921). En "La Catedral de Málaga" (1921) olvida un tanto las preferencias de que hablamos y el registro cálido, que habrá de ser el mejor prodigado por estar en consonancia con . su "constante" anímica, impregna los elementos del cuadro de cierta gozosa conciencia. Las tres exposiciones que el artista realiza en Santiago a su regreso de Europa, entre los años 1922 y 1923, objetivan con esplendidez la primera etapa en el camino de su evolución integral.

Luego, sus diez años de vida provinciana le entregan el secreto del paisaje y del hombre nativos. La visión ya madura del artista, respira un animismo entrañado y latente al par que una fuerte vitalidad plástica, que diríase fustigada por las fuerzas elementales del medio, sin que por ello su paleta deje de crear esa sugestión saludable y feliz, inherente a toda su obra. El registro cálido, con sus bermellones y sus azules profundos y alados, palpitantes, lo lleva a todas las soluciones. Aun las gamas verdes, frías por definición, son transmutadas por el embrujo en ritmos excitantes y sensuales.

La característica insurgencia que señaló la vida del hombre, la exuberancia de su sangre jubilosa, libraron al artista de la neurosis que secreta $\mathrm{u}$ ostensiblemente contamina y disminuye lo creado. $\mathrm{Ni}$ uno solo de sus dibujos, ninguna de sus telas, aun aquellas pintadas en los días negros de sus últimos años santiaguinos, acusan el más leve rasgo de amargura.

Es uno de los poquísimos pintores que pudo construirse y crecer después de romper con el medio burgués que siempre ha sido verdugo del talento. Hemos dicho que el hombre y el artista eran en Pedro Luna un solo ser. Esto constituye milagro y razón de la obra artística. El mundo infinito de este pintor, negado a la medida social 
y a la escolástica, pudo sobrevivir en nuestro medio gracias a la indudable sugestión que ejerció sobre los suyos, amigos y extraños.

Las obras de este período en que el artista sólo vive para satisfacer aquel universo inaudito se cuentan por centenares. El paisaje de la Frontera, profundo y lavado por las lluvias, encantado de súbito por sus soles huidizos, el indígena recio y contenido, viven en sus telas de la década provinciana. Anotemos: "El bodegón" (1927), "Indias lavando" (1928), "Bautizo araucano" (1925), "Sacando la barca” (1930), "La montaña” (1934) y su famoso "Guillatún” (1934).

Antes de su viaje a Viña del Mar en 1954, Pedro Luna ha permanecido casi veinte años en Santiago y sus obras de este lapso llenarían las salas de un museo. Pintaba de todo y aun aceptaba reproducir fotografías y restaurar cuadros familiares de diversa naturaleza. El desorden de su vida, ya lo hemos dicho, disolvía el dinero recibido, que no era mucho, pues el pintor no sabía pedir por sus obras. Aparte algunos encargos hechos a disgusto, la mayoría de sus trabajos de este oscuro y tortuoso período, acusan una calidad indiscutible tanto en la composición como en el despliegue cromático, airoso e insinuante. El maestro alcanzaba su cima y, no obstante, la faena superior lo incitaba como antaño en eterna búsqueda del acento que parecía escapar siempre. Conservamos de su obra santiaguina, entre otros, un cuadro de mayores dimensiones que las usuales en las obras de Luna y que él repitió en versiones aproximadas: "La procesión", compuesto sobre un motivo santiaguino. Aquel equilibrio, robusto, profundo e incitante que parece constituir la superior conquista de su paleta, respira en el cuadro mencionado. Recordamos algunas otras telas de esta época: un "Mocetón araucano", un "Beethoven" y varios motivos campesinos de los alrededores de Santiago.

Ya instalado en Viña del Mar, empieza a trabajar con nuevo brío. Los tres años finales, vividos en la ciudad jardín, definen la última etapa de su obra ya culminada en Santiago, así como tejen el duro eṕlogo de su desafío al destino. Un ambiente propicio a su persona favorece su producción. Un amigo suyo, vinculado en la vida culta de Valparaíso y Viña del Mar, estimuló este cambio. 
El examen de sus últimos cuadros destaca una admirable conjugación cromática y un severo equilibrio total, signos de gloria en la contienda del artista con su demoníaca sombra. No hablo de virtuosismo, ni mucho menos, menguada conquista de quienes forjan desde fuera hacia adentro, para conseguir sólo la perfección técnica. Pedro Luna, a la luz de estas últimas muestras, ofrece la madurez del creador, siempre excitado por la hoguera secreta, imperativo que no le permitió el lento lucubrar y, sí, disparar su insólito sentido de la imagen plástica.

Menos ardiente, menos fustigante, quizás, su obra de este lapso final se resuelve en un registro pleno de misteriosa lucidez y en el cual la gozosa concertación de los matices ennoblece los valores dominantes y las formas.

Tal plenitud pudiera traducir la expresión de una conciencia que llega a enfrentar el fondo de la existencia humana. 